\title{
Tetanus Toxoid Vaccine
}

National Cancer Institute

\section{Source}

National Cancer Institute. Tetanus Toxoid Vaccine. NCI Thesaurus. Code C2660.

A preparation of formaldehyde-deactivated toxin isolated from the bacterium Clostridium tetani. Tetanus toxoid is used for booster injection and can stimulate the production of antitoxin antibodies. This agent may be used as an adjuvant in cancer vaccines. 